\title{
Pharmaceutical services in primary health care: dissatisfaction among users, managers and pharmacists
}

\author{
Manuela Martins Cruz ${ }^{1}$, Karla Oliveira dos Santos Cassaro Heringer', \\ Cristiane Lyrio ${ }^{1}$, Girlandia Alexandre Brasil ${ }^{1}$, Ewelyne Miranda de Lima ${ }^{1}$, \\ Denise Coutinho Endringer ${ }^{1}$, Dominik Lenz ${ }^{1}$, Ana Maria Bartels Rezende', \\ Tadeu Uggere de Andrade ${ }^{\oplus 1^{*}}$
}

${ }^{1}$ Pharmaceutical Sciences Department. Vila Velha University, Espirito Santo, Brazil

\begin{abstract}
To assess the performance indicators for pharmaceutical services (PS) in primary health care (PHC), the level of satisfaction with pharmacy services among users and managers / pharmacists' impressions in relation to the findings were evaluated. The study used mixed methods, including a retrospective and descriptive study of the performance indicators for PS in PHC, an observational study on the level of satisfaction and a qualitative study of users' perception of pharmacy services at Health Units. Managers and pharmacists' impressions of the study results were also collected. Only $44.4 \%$ of pharmacies had a full-time pharmacist. From the establishments visited, $5.3 \%$ did not have an air-conditioned environment, and only $33.3 \%$ of the items essential to the Good Practices of Storage of Medicines and Supplies criteria were fulfilled. Although $77.9 \%$ of the prescribed medicines were dispensed, it did not reach the $80 \%$ standard. The satisfaction level of users was $3.2 \pm 0.6$, indicating dissatisfaction with pharmacies' services. By means of an evaluation of each item within the questionnaire, it was possible to observe that variables related to pharmaceutical care presented low scores in relation to other domains, thus evidencing the fragility of the pharmaceuticalpatient relationship in users' perception. Managers and pharmacists suggested that these results were related to the inadequate physical infrastructure of pharmacies, work overload, lack of recognition and undervaluation of pharmacists, lack of interaction within the PHC team, high turnover of pharmacists, and lack of PS prioritization by the administration. PS in PHC has structural and organizational weaknesses that require changes. In general, users are dissatisfied with pharmacies' services, especially with pharmaceutical care.
\end{abstract}

KEYWORDS: Pharmaceutical Services. Patient satisfaction.

\section{INTRODUCTION}

Pharmaceutical service (PS) provided by Brazil's Unified Health System (Sistema Único de Saúde - SUS) (Brasil, 1990) is designed to fulfill multiple functions that aim to facilitate access and rational use of medicines

*Correspondence: T. U. de Andrade. Departamento de Ciências Farmacêuticas. Universidade Vila Velha. Espírito Santo, Brasil. Rua Comissário José Dantas de Melo, 21. Boa Vista. 29102-770 - Vila Velha - ES, Brasil. Número: +55-27-3421-2048. E-mail: tadeu.andrade@uvv.br. in order to promote, protect and recover individual and collective health (Brasil, 2004).

To guarantee population's regular and continuous access to medicines that meet their needs (Brasil, 2015), the Federal Government is responsible for selecting and defining the National List of Essential Medicines (RENAME). This List governs the prescription and dispensation of medicines (Brasil, 2015), and is also a reference to standardizing state and municipal medicine lists (Brasil, 2007); municipalities define the Municipal List of Essential Medicines to guarantee the availability of medicines at the level of primary health care (PHC). 
Due to the significant complexity of the actions it involves and the volume of financial resources allocated to it (Silva et al., 2016), PS management today represents a challenge in public health; it is also a deficient area in municipal management (Pinto, Osório-de-Castro, 2015). Additionally, PS generally deals with under-qualified pharmaceutical services, faulty functioning, and inefficient management of public resources while serving a population increasingly in need of medicines (Bruns, Luiza, Oliveira, 2014); therefore, planning, organizing and executing PS activities represent a concern for SUS managers and other health professionals (Silva et al., 2016).

In the context of PS performance and qualification challenges in $\mathrm{PHC}$, the need to investigate this aspect of health policy is evident. This is possible with the use of indicators, which serve as instruments to facilitate the verification of services conditions (Volpato, Padial, 2014). These indicators are classified in three categories: structural indicators measure whether human, material and financial resources are available in the quantity and quality necessary for the development of health services; process indicators relate to the efficiency of the activities carried out; and result indicators track changes in the health status of the population resulting from the care received (Volpato, Padial, 2014; Rieck, 2002).

Regarding the obvious advances in PS development, there is data related to the evaluation of PHC pharmacies. It is essential to carry out further studies related to satisfaction among users of these services in order to promote beneficial advances for public health (Bonadiman et al., 2018). Health system user satisfaction is one of the main instruments that contribute to improve the quality of the services offered (Alturki, Khan, 2013); it can be understood using both quantitative and qualitative approaches.

Moreover, it is useful to consider the perceptions of the various subjects involved in the planning and execution of health services (Tuzzo, Braga, 2016), being essential to include them in this evaluation process. A focus group methodology is an important tool to do this, since it makes possible to understand human groups' perceptions through interactions among participants discussing a theme suggested by the researcher (Tanaka, Melo, 2001).

It is also important to triangulate data when considering different approaches, methodologies and actors involved in the performance of health services. This allows predicting a broad vision and multiple perspectives on the same problem (Tuzzo, Braga, 2016).
Within this conception, Bruns et al. (2014) demonstrated the need to expand the methodologies used in the studies of PS' management problems, as difficulties persist in analyzing PS performance with existing methodologies.

Therefore, the objective of this study was to evaluate the performance of PS actions in PHC, the satisfaction and perception of users regarding the services offered by pharmacies in health units (HU), and the impressions of managers and pharmacists on the verified data.

\section{METHODS}

\section{Description of place of study}

The Vila Velha municipality has an approximate population of 486.388 inhabitants, being the second most populous city in Espírito Santo State. The city is divided into 91 (ninety-one) neighborhoods grouped into 5 (five) health regions (IBGE, 2016; VILA VELHA, 2013).

Vila Velha's PS is structured by one coordination - located at the Municipal Secretary of Health and subordinated to the PHC undersecretary-, one warehouse and 18 pharmacies distributed in $18 \mathrm{HU}$, where essential medicines are dispensed (VILA VELHA, 2016). The warehouse and all pharmacies have pharmacists; overall, PS has 27 pharmacists including coordination, warehouse, and Pharmacy and Therapeutic Committee (PTC) pharmacists (VILA VELHA, 2013).

\section{PS actions in PHC performance analysis}

This study includes a retrospective description of the performance of PS actions in PHC from 2015 and 2016. Visits to HU and warehouses were conducted between March and May 2017 to evaluate its performance through management indicators, such as structure, process and result. In total, 19 services were evaluated.

For this, data regarding the structure, process and result of PS was collected according to criteria created and validated by Rieck (2002) and adapted by Volpato, Padial (2014) with further adjustments in the present study.

Altogether, 24 (twenty-four) indicators were used -16 structure indicators, 4 process indicators and 3 result indicators. These indicators were (see Table I to III):

Structure Indicators: number of pharmacies and warehouses with pharmacists; number of pharmacies and warehouses with full-time pharmacists; if PTC 
was constituted and active; number of pharmacies and warehouses fulfilling the Adequacy of Good Practices of Storage of Medicines and Supplies criteria.

Process Indicators: evaluation of the strategy and/or tools used for inventory control of medicines and supplies.

Result Indicators: evaluation of medicine supply, number of prescriptions fully met, and quantity of medicines prescribed and dispensed.

\section{Evaluation of user satisfaction and perception regarding the services offered by HU pharmacies}

Two approaches were used regarding the evaluation of user satisfaction and perception of the services offered by HU pharmacies between March and May 2017.

For satisfaction evaluation, an observational quantitative survey was performed. According to PS Coordination of Vila Velha, a total of 42,852 users were attended at the pharmacies. This number was used to calculate the sample size of users to be interviewed considering a $95 \%$ confidence level and a 5\% margin of error; in total, 225 users of these pharmacies were included in the survey. The calculated sample was stratified by the 18 HUs of this municipality according to their population coverage and average number of monthly visits performed, indicating the sample of users to be interviewed at each pharmacy.

User satisfaction data were collected using an interview questionnaire developed by Kucukarslan, Schommer (2002) and adapted, translated and validated in Portuguese by Correr et al. (2009). This instrument evaluates both the services provided by the pharmacist and the services of the pharmacy in general; it has a five-point Likert's intensity scale for each question (a total of 20). The interviewee chooses the answer that best represents his or her opinion, with the lowest number representing the "bad" option and the highest the "very good" option. The questionnaire has two fields: eight out of the 20 questions are related with general services and structural aspects of the pharmacies and the remaining 12 questions were related to pharmaceutical care (PC) and related aspects (Correr et al., 2009).

The level of satisfaction was expressed for each question and for the questionnaire as a whole. Users were also classified as satisfied (score equal to or greater than 4) and not satisfied (score less than 4) (Cassaro et al., 2016). The interviews were not conducted by the researcher, but by a person trained for that purpose. The visits were performed on random days -only one to each HU pharmacy- to collect the information needed for the survey.

A qualitative method was used to collect users' perception. From the 225 users interviewed, 32 agreed to further participate in the qualitative approach of the study. Semi-structured questions were used, which allowed the interviewer to understand users' perception regarding the structure of the pharmacy and the assistance provided by the pharmacist.

With authorization of the interviewees, testimonies were recorded using a digital recorder. These statements were transcribed, edited, and passed through a free-floating reading in which the researcher was allowed to "invade" the impressions (Bardin, 1977) and delimit the responses. The latter were tabulated and organized according to the Discourse of the Collective Subject (DCS) technique, in which key expressions of each deposition were selected and combined according to similarity between their central ideas. This process results in the DCS written in the first person (Lefevre, Lefevre, 2003).

\section{Managers and pharmacists' impressions of PS actions performance in PHC and users' satisfaction and perceptions regarding the services offered by HU pharmacies}

This part of the study included professionals working in the management and coordination of PS and pharmacists at HUs' warehouse and pharmacies. For the qualitative approach, managers and pharmacists' universe was considered. Six professionals working in the management and coordination of PS and ten pharmacists participated in this phase of the study.

Managers and pharmacists' impressions of PS actions performance in PHC were measured through indicators and users' satisfaction and perceptions of services at HU pharmacies were collected separately by using focus groups conducted between September and October 2017. This methodology provided data that addressed the main causes and challenges related to the results presented. It also captured their perspectives on how to change the situations described.

Three focus group meetings were conducted of one hour and 30 minutes each; they were conducted by a facilitator and two auxiliary researchers. All discussions used the following roadmap: a presentation of the group's 
objectives, including how to conduct the discussion, its duration and the central topic; a presentation of PS actions performance in PHC measured through indicators and data on users' satisfaction and perceptions of HU pharmacies' services; and the presentation of the question in focus "what are the causes and difficulties that lead to what was presented, and what solutions would improve the results?". This was followed by a debate recorded with two voice recorders with the participants' approval. The important aspects of the discussion were also registered separately in writing by the auxiliary researchers.

The recordings of the focus group discussions were repeatedly listened in order to record the most relevant speech fragments that responded to the central subject of the discussion. After transcription, the speeches passed through a floating reading, the statements were edited, and the results were interpreted (Bardin, 1977).

For presentation of results, the methodological resource of data triangulation was used (Tanaka, Melo, 2001). The results of PS actions performance in PHC measured through indicators were related to the impressions of managers and pharmacists regarding these results. From this perspective, data related to the perceptions of users regarding the services offered by pharmacies were associated with the impressions of managers and pharmacists. This process qualified the objective of the study, as the subjects involved in the process could do it with more authority.

\section{Inclusion and exclusion criteria}

Concerning health professionals, general and PS managers, warehouse pharmacists, and HU pharmacies of Vila Velha were included. With respect to users, the ones older than 18 years old who were able to respond to the interviews at the time of the visit and agreed to participate were included. Managers and pharmacists that did not want to take the interviews and/or to participate in the focal groups were excluded.

\section{Statistical analysis}

The quantitative data were expressed as the mean \pm standard deviation (SD).

\section{Ethical approval}

The Ethics and Research Committee on Human Beings of the Vila Velha University approved the study (Protocol $\left.n^{\circ} 1.920 .600 / 2017\right)$. After inclusion and exclusion criteria were met, participants signed the Free and Informed Consent Term form.

\section{RESULTS}

\section{Profile of pharmacists working in the services studied}

From the pharmacists approached, 21 (77.8\%) were female and $6(22.2 \%)$ male.

The age group with the highest frequency was 3549 years $(51.9 \%)$, followed by $18-34$ years $(40.7 \%)$ and 50-60 years $(7.4 \%)$.

Most pharmacists, 12 (44.4\%), had worked in Vila Velha for $1-5$ years, followed by $11(40.7 \%)$ with less than 1 year of experience in this municipality, $3(11.1 \%)$ with 6-10 years of experience, and 1 (3.7\%) with more than 10 years of experience.

Fifteen $(55.5 \%)$ pharmacists had a temporary contract and 12 (44.4\%) had permanent positions.

Regarding professional qualification, 16 pharmacists $(59.3 \%)$ had general qualifications, followed by 5 $(18.5 \%)$ qualified in clinical analysis, 3 (11.1\%) without qualification, 2 (7.4\%) qualified in cosmetology, and 1 $(3.7 \%)$ qualified in industry.

Nineteen (70.4\%) pharmacists graduated from private educational institutions and the remaining 8 (29.6\%) from public institutions.

Eighteen (66.7\%) pharmacists worked exclusively in Vila Velha and the other $9(33.33 \%)$ had other employment bonds.

\section{Structure, process and result indicators of PS}

The structure indicator revealed that only $8(42.1 \%)$ pharmacies in HUs had full-time pharmacists.

In contrast, some results were positive and 5 items (38.5\%) met the requirements for compliance with the Adequacy of Good Practices of Storage of Medicines and Supplies criteria, namely: specific site for controlled medicines; specific location with temperature control for thermolabile medicines; receivement of medicines: physical integrity, quantity, batch, and expiration date; storage and final destination of expired medicines written and followed procedures; medicines stocked with older batches in front so they are used first.

Additionally, although some indicators are satisfactorily fulfilled -such as the presence of an 
active PTC, only 5 (38.5\%) out of 13 items necessary to guarantee performance were adequately fulfilled by the analyzed establishments according to the Adequacy of Good Practices of Storage of Medicines and Supplies indicators. The main problems found were related to acclimatization and medicine storage conditions (Table I).

TABLE I - Structure indicators (E1, E2 and E3) of PS in PHC, in 2015 and 2016.

\section{Indicators}

Structure

\begin{tabular}{lcc}
\hline E1 & N & $\%$ \\
\hline Pharmacies with pharmacists & 18 & 100 \\
Pharmacies with full-time pharmacist & 8 & 44.4 \\
\hline E2 & Yes & No \\
$\begin{array}{l}\text { Pharmacy and therapeutic committee } \\
\text { constituted and active }\end{array}$ & Yes & - \\
\hline
\end{tabular}

E3

Adequacy of Good Practices (AGP) of

N $\%$

storage of medicines and supplies

Air-conditioned environment

$18 \quad 94.7$

Sufficient space for medicine

storage and routine execution

$8 \quad 42.1$

Illumination, ventilation, temperature

and humidity controlled

$17 \quad 89.5$

Clean environment, without dust, contamination, waste or animals

$15 \quad 79$

Uniform floors, walls and ceiling, no

cracks, holes, leaks or escapes

$13 \quad 68.4$

Specific site for controlled medicines

$19 \quad 100$

Specific location with temperature

control for thermolabile medicines

Specific location for medicines near expiration
TABLE I - Structure indicators (E1, E2 and E3) of PS in PHC, in 2015 and 2016.

\section{Indicators}

Structure

\begin{tabular}{ll}
\hline E1 & N $\%$ \\
\hline
\end{tabular}

Preceivement of medicines: physical integrity, quantity, batch, and expiration date

Storage and final destination of expired medicines: written and followed procedures

Expired products in stock

Periodic inventories, with record of divergences and justifications

Medicines stocked with older batches

in front, so they are used first

Essential AGP items for medicines and supplies fully met

PS' process and result indicators had better results. From 19 establishments analyzed, only one (5.3\%) still registered manually items in stock (Table II). From the 3 indicators analyzed, only one $(33.3 \%)$ did not reach the standard set $(80 \%)$, as only $77.9 \%$ of prescribed medicines were dispensed (Table III).

TABLE II - Process indicators (P1 and P2) of PS in PHC, in 2015 and 2016.

\section{Process \\ P1}

Indicators

Control of medicine stock

$\begin{array}{ll}\text { Daily entry and exit of medicines } & \text { N }\end{array}$

$\begin{array}{lrr}\text { Computerized } & 19 \quad 100\end{array}$

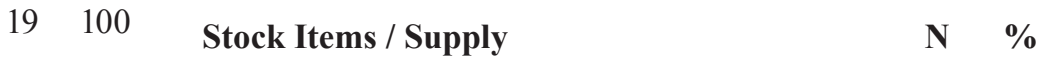

14 Manual $\quad \begin{array}{llll}14 & & 5.3\end{array}$ 
TABLE II - Process indicators (P1 and P2) of PS in PHC, in 2015 and 2016.

\begin{tabular}{lll} 
Indicators & & \\
Process & & \\
P1 & & \\
Control of medicine stock & N & $\%$ \\
\hline Daily entry and exit of medicines & 18 & 94.7 \\
\hline Computerized & N & $\%$ \\
P2 & & \\
Pharmacy warehouse supply index tracking & 18 & 100
\end{tabular}

TABLE III - Result indicators (R1, R2 and R3) of PS in PHC, in 2015 and 2016.

\section{Indicators \\ Result}

\begin{tabular}{lc}
\hline $\mathbf{R} 1$ & $\mathbf{\%}$ \\
\hline $\begin{array}{l}\text { Supply (standard }=80 \%) \\
\text { R2 }\end{array}$ & 82.6 \\
$\begin{array}{l}\text { Prescriptions fully met (standard } \\
=\text { minimum 60\%) }\end{array}$ & 78.1 \\
\hline R3 & $\mathbf{\%}$ \\
$\begin{array}{l}\text { Medicines prescribed and } \\
\text { dispensed (standard }=80 \%)\end{array}$ & 77.9 \\
\hline
\end{tabular}

\section{Socioeconomic data of users}

From all users who participated in the study, 172 (76.4\%) were female and $53(23.6 \%)$ male.

The age group with the highest frequency was 3549 years $(29.8 \%)$, followed by $50-60$ years $(27.6 \%)$, and $18-34$ years $(26.2 \%)$. Sixteen per cent of the respondents were older than 60 years.

Most of the users had finished high school (46.7\%), followed by $22.5 \%$ who had incomplete primary education and $18.2 \%$ who had complete primary education. Only one user was illiterate. Fourteen (6.2\%) users had incomplete higher-level education and 14 $(6.2 \%)$ others complete higher-level education.

The average monthly household income was 1-2 minimum wages $(73.8 \%)$.

\section{User satisfaction with services offered by pharmacies}

The level of general satisfaction of the users was $3.2 \pm 0.6$, indicating that most of them are dissatisfied with the services offered by HU pharmacies.

Regarding general satisfaction, at the time, each item of the questionnaire was evaluated separately (Table IV); it was possible to observe that the variables related to PC and therapy management (questions 4, $7-12,15$ and 17-20) presented low scores in relation to the other domains linked to the pharmacies' general services (questions 1-3, 5, 6, 13, 14 and 16), which had better scores.

TABLE IV - Overall satisfaction levels for each item of the satisfaction questionnaire for pharmacy services, mean and standard deviations.

\begin{tabular}{lc}
\hline \multirow{2}{*}{ Question } & \multicolumn{1}{c}{ Total } \\
\cline { 2 - 2 } & Mean $\pm \mathbf{S D}$ \\
\hline $\begin{array}{l}\text { 1. The professional appearance } \\
\text { of the pharmacy }\end{array}$ & $3.8 \pm 1.0$ \\
$\begin{array}{l}\text { 2. The readiness of the pharmacist } \\
\text { to answer your questions }\end{array}$ & $3.9 \pm 1.1$
\end{tabular}

3. The pharmacist's professional relationship with you

$3.98 \pm 0.95$

4. The ability of the pharmacist to warn you about problems you $2.8 \pm 1.6$ might have with your medicines

5. The readiness in filling your prescription $\quad 4.0 \pm 1.9$

6. The professionalism of the employees of the pharmacy $4.0 \pm 0.9$

7. A pharmacist explaining the action of your medicines 
TABLE IV - Overall satisfaction levels for each item of the satisfaction questionnaire for pharmacy services, mean and standard deviations.

\begin{tabular}{ll}
\hline & \multicolumn{1}{c}{ Total } \\
\cline { 2 - 2 } Question & Mean \pm SD \\
\hline
\end{tabular}

8. The interest of the

pharmacist in your health

$2.5 \pm 1.6$

9. The help of the pharmacist in

the use of your medicines

$2.7 \pm 1.6$

10. The commitment of the

pharmacist to resolve the problems

you have with your medicines

$2.7 \pm 1.6$

11. The responsibility that the pharmacist assumes with your treatment

12. The orientation from the pharmacist on how to take your medicines

$2.7 \pm 1.6$

13. Its pharmacy services in general

$3.6 \pm 1.2$

14. The pharmacist answers

to your questions

$3.8 \pm 1.1$

15. The effort of the pharmacist in maintaining or improving your health

$2.5 \pm 1.6$

16. The courtesy and respect shown

by employees of the pharmacy

$4.0 \pm 0.95$

17. The privacy of conversations

with the pharmacist

$2.7 \pm 1.6$

18. The effort of the pharmacist

to ensure that their medicines

have the expected effect

19. The explanations of the

pharmacist about the possible

$2.5 \pm 1.6$

adverse effects of medicines

20. The time the pharmacist

provides for you

$3.7 \pm 1.0$

Overall average

$3.2 \pm 0.6$

Data are expressed as the mean \pm SD
In detail, the lowest scores of user satisfaction associated to the variables related to PC and therapy management were linked to the interest of the pharmacist in user health, the responsibility that the pharmacist assumes with the user treatment, the effort of the pharmacist to ensure that the users' medicines have the expected effect, and the explanation of the pharmacist about the possible adverse effects of medicines (questions 8, 11, 18 and 19).

Higher levels of user satisfaction can be observed when emphasizing some issues related to general service fields of pharmacies, mainly: the readiness in prescription service, the professionalism of pharmacies' employees, and courtesy and respect from employees (questions 5, 6 and 16).

\section{Users' perception of services offered by pharmacies}

Thirty-two selected users, who agreed to participate in the study, were interviewed.

Considering that the quantitative approach of user satisfaction can be complemented by their perception, we also collected, through the DCS technique, users' testimonials; therefore, from now on, we shall present our results more accurately, considering users' perceptions of public pharmacies services in Vila Velha.

The results shall be presented through the four central questions of the study, which compose the categories of discourse analysis. For each of them, users' testimonials, represented by DCS, shall be exposed.

\section{Regarding the service offered by pharmacies}

The initial question was related to the perceptions of users regarding the service offered by HU pharmacies, such as the following example:

"[...] I'm not satisfied! [...] Every time I come I have a problem [...] they did not want to help me and give me the medicines at the first pharmacy [...] Sometimes when we come to get the medicine later, we cannot because they have already taken care of it in the morning [...] I have to be patient and wait for them to give me my medicine [..] They need to improve a lot [...]" (DCS)

It identifies, from users' arguments, limitations for a quality service accomplishment; in this case, medicine shortage: 
"[...] the worst thing is the lack of medicine! [...] Yesterday I had already looked for the medicines in three pharmacies, but there wasn't anything. I hear now: it's been over a year since Cephalexin has not been in stock. [...] Who does not have the conditions to buy it is screwed, right?! But that's not the pharmacist's fault, so I blame the city hall" (DCS)

Regarding the infrastructure of pharmacies

About this question, users answered:

"[...] I think it's lousy! There is no comfort. There is not a covered place for us to wait to receive the medicine. We await under the sun and the rain [...] There should be a better place for people to sit down, right?! [...]it could improve a little bit [...] (DCS)

"[...] More or less, it does not have structure and needs a pharmacy with a better structure. Could have the divisions for the medicines. The employees have nothing in there to refrigerate the medicine; a badly refrigerated medicine gets spoiled and people's money is thrown away [...] (DCS)

"[...] I think that the pharmacy is too small [...]. Sometimes there are many people waiting and no place to sit. And that's a very important thing, comfort for the people who are waiting [...]" (DCS)

\section{Regarding the care shown by pharmacy professionals}

The third question elicited users' perceptions regarding the care taken by the pharmacy professionals:

"[...] When they are stressed or with some problem, the service is not good. If you ask, they explain and clarify everything you have to do. Now, if you ask nothing, they will not tell you anything. She simply (the clerk) read the bull, took the medicine and gave it to me; there were no words at all. I would like to ask for employees to be better trained to work in the industry, to be better psychologically trained and not bring problems from home to work, so that they won't be dissatisfied thinking that they are doing us a great favor, because we notice their dissatisfaction [...]" (DCS)
Regarding the guidance offered by pharmacy professionals

Regarding the guidance offered by the pharmacy professionals, the DCS was performed.

"[...]conversation is fast, but guidelines are surely important; without them there is no way to take the medicine! They (pharmacy clerks) give advice on how to take the medicine and the day to pick up. Before, I did not even know how to give myself an injection and I thought that taking the medicine would solve the problem [...]. With guidelines we stay up to date, carefree and take the medicine correctly at the right time and in the way they teach us. This helps a lot!" (DCS)

"[...] there is no time. We never get instructions from the pharmacy; they just look at the prescription, stamp it, take the medicine, and give it to the patient. Since I started going to this post, it is always been a matter for doctors, not pharmacists, do you understand? [...] If we received some guidance and explanation on how to take the medicine, it would be important! [...]" (DCS)

\section{Results from focal groups with managers and pharmacists}

From PS actions performance measurement of users' satisfaction and perception, it was possible to elaborate speeches and record the impressions of 6 managers and 10 pharmacists who participated in the qualitative phase of this study; thus, it was possible to relate managers and pharmacists' opinion about pharmacists' presence in pharmacies:

"[...] professionals are dissatisfied [...] what impacts [...] not having the professional throughout the period, because many of them leave [...]" (Managers)

"[...] The pharmacy must service all day [...]" (Pharmacists)

In relation to pharmacies' structure, the Good Practices of Storage of Medicines and Supplies criteria, processes, and results of PS, managers and pharmacists had the following impressions:

"[...] I think that physical space is what jeopardizes most of the pharmacies [...]"; "[...] medicines are on the floor [...]” (Pharmacists) 
"[...] The structure of the whole HU does not contain the volume of users it serves, the humanization and storage of medicines [...]" (Pharmacists)

"[...] the problem is that the idea of management is to open up a HU no matter where, there is no previous planning [...]" (Managers)

"[...] we do not have computers and people to type everything into the system, and this increases the queues of people waiting for the medicines [...]" (Pharmacists)

"[...] The bureaucratic part takes immense time [...]" "[...] There must be more pharmacists [...]” (Pharmacists)

"The pharmacy is not within the management priorities [...]” (Managers)

In this area, some comments of the managers and pharmacists contributed to design the improvements in the structure, processes and results of PS, as we can see as follows:

"[...] Full-time pharmacists in pharmacies [...]" (Pharmacists)

"[...] Only with a satisfactory wage everyone would work [...]" (Pharmacists)

"[...] Improve the physical area and layout of the pharmacy [...]" (Pharmacists)

"[...] pharmacies should have a room for storage of materials and medicines, a space for receiving merchandise and front room with service counters [...] equipped with pallets and shelves [...] shelves suitable for bins [...]" (Pharmacists)

\section{"[...] a better system [...]" (Pharmacists)}

About medicine dispensation managers and pharmacists said:

"[...] We see prescribers who do not know and some who are not even interested in knowing what is standardized in the network [...]" (Managers)

"[...] But it is also due to our lack of medicines in the network [...]" (Managers/Pharmacists)
"[...] it has to improve the pharmaceutical-medical interface [...]" (Managers)

"[...] Doctors should be trained to know what is stocked in pharmacies [...] there's no use in prescribing what pharmacies do not have [...]" (Managers)

“[..] We have to plan [...]” (Managers)

Concerning user satisfaction, managers and pharmacists had the following impressions and solution proposals to guarantee user satisfaction:

"[...] The amount of HU is infinitely less than it should be [...]" (Managers)

“[... missing human resources [...]” (Managers)

"[...] there are HUs that do not really have covered spaces and they (patients) remain waiting in the rain [...]" (Managers)

“[...] Dissatisfaction of professionals [...] with salaries [...] many duties [...] insecurity [...]" (Managers)

"[...] PS is seen [...] as something much further, they do not see the pharmacy as a place that has a professional available to ask questions [...]" (Pharmacists)

"The physical structure and volume of services of pharmacies do not allow pharmaceutical care..." (Pharmacists)

"[...] the structure does not guarantee a private conversation between the pharmacists and the patient [...]" (Pharmacists)

"[...] To increase the amount of HUs to meet the great demand and to be able to provide pharmaceutical care to patients [...]" (Pharmacists)

"[...] Improving the physical structure of pharmacies [...]" (Pharmacists)

"[...] While salaries do not improve, there won't be pharmacists; without pharmacists there won't be any of that (improvements) and dissatisfaction will continue [...]” (Pharmacists) 
"[...] a pharmacist for dispensation, one for stock control and another one for the other activities, since we have to do everything: care, logistics and management [...]" (Pharmacists)

"[...] pharmacists would be freer to play their roles and not deliver medicine [...]" (Pharmacists)

“[...] In order to improve clinical care, pharmacists need more training in the technical field [...]" (Managers)

\section{DISCUSSION}

The main objective of this study was to describe the scenario of the PS provided by the Primary Care of the public health system of a Brazilian municipality using qualitative and quantitative approaches. Although studies describing PS in Brazilian public health system already exist, it is not from our knowledge any studies evaluating PS under the optics of management indicators and user satisfaction, linking these results with the perceptions of users, managers and pharmacists in relation to the structure and services provided.

The results of this study indicate that there are gaps in the infrastructure, personnel capacity, and quality of the health care provided in the PS assessed.

Bonadiman et al. (2018) have also evaluated the satisfaction of municipal public pharmacies' users with the same quantitative approach of the present study. They also found low scores of satisfaction (around 3). This result was similar to ours regarding the quantitative analysis.

In this sense, our data revealed the fragility in the pharmaceutical-patient relationship; this is consistent with the data reported by Cassaro et al. (2016), who also found low scores for the clinical performance of pharmacists in SUS' public pharmacies.

The scenario identified in the studied municipality -demonstrated by PS results and the perception of users, managers and pharmacists- converges with data from previous studies, which showed that the absence of fulltime pharmacists in pharmacies hinders communication with users and impedes their adherence to treatment (Prevedello, Busato, 2014), revealing how essential their constant presence is (Mendes et al. 2015).

Routine development in pharmacies with only one part-time pharmacist contributes to impoverish the quality of the service provided (Correr et al., 2009). Souza Júnior et al. (2015) observed a relationship between reduced user satisfaction and assistance quality provided by pharmacists.

Alves et al. (2015) revealed that the fragility of the employment contract, signed by means of temporary contracting, makes it impossible to continue and improve activities essential to health services that can also be understood through the data of our study.

Concerning this area, one of the guidelines of the SUS management pact is a policy that defines the commitment to strengthen human resources as the responsibility of municipal health departments (Silva et al., 2016); however, this policy is apparently not well implemented in the PS area of the municipality evaluated.

In addition, it is know that the Good Practices of Storage of Medicines and Supplies criteria must be guaranteed in order to promote the rational use of medicines (RUM). In this context, some results were positive and 5 items $(38.5 \%)$ met the requirements for compliance with this guideline. According to Bruns et al. (2014), to ensure these good practices, some processes must be taken into account, including checking medicines at the time of receivement, existence of specific places for the storage of thermolabile and photosensitive medicines, medicine organization to facilitate quick access, and medicines' integrity and quality safeguard.

However, it turns out that our results also showed non-compliance with these requirements, as only $5(38.5 \%)$ of the 13 items necessary to guarantee performance were adequately fulfilled; this contraries the RUM, since there is no guarantee of quality preservation nor adequate routines that involve them (Rieck, 2002).

For Bruns et al. (2014), inadequate physical space, insufficient refrigeration and the presence of infiltrations are all factors that impair the quality of medicines and discourage the professionals involved in pharmacy routines.

In this respect, users, managers and pharmacists expressed the need for improvements in the structure and organization of pharmacies due to the lack of sufficient space for storing medicine, ideal infrastructure for promoting $\mathrm{PC}$ and user accommodation.

Users expect well-structured environments and comfort to be guaranteed; this corroborates with the data found by Ayalew et al. (2017), in which the majority of the respondents were dissatisfied with the insufficient availability of seats in the waiting area. 
Privacy during conversations between users and professionals is among the variables that presented the lowest user satisfaction ratings (Bonadiman et al., 2018). Many pharmacies are not structured with a private room to converse with users and provide the necessary guidelines (Angonesi, 2008; Leite et al., 2017). In this regard, literature points the need for appropriate environments to guarantee care quality. To enhance the services offered by pharmacies, physical structure must be adequate and working conditions of professionals improved (Leite et al., 2017).

Our data also revealed that the best results related to medicinestock controlreinforce the belief thatcomputerized systems would minimize errors that may occur in manual processes, both for management and assistance provided to health service users. Computerization could streamline work processes to ensure optimal management of medicine stocks (Marin et al., 2003).

Additionally, one possible explanation for the partial dispensing of prescribed medicine, one of the problems found in the municipality, is prescribers' lack of familiarity with standardized medicine (MagarinosTorres et al., 2014).

Likewise, Helena et al. (2015) reported that only $75 \%$ of the medicines prescribed were dispensed. In this scenario, it is assumed that one of the ways to guarantee prescriber's knowledge on medicine standardization is through his or her interaction with pharmacists (Arruda, Bosi, 2017).

For users, there is a direct relationship between ensuring access to medicines and care quality (Arruda, Bosi, 2017).

The managers suggested that medicine shortage also influenced dispensing, which has also been found in other studies (Helena, Andersen, Menoncin, 2015; Bonadiman et al., 2018; Rover et al., 2017). Shortages can be triggered on account of misdirected prioritizing and purchasing by municipal managers and responsible professionals (Prevedello, Busato, 2014).

Regarding the care and guidance given by pharmacy professionals, it is noticed that the users, when referring to pharmacists, do not address issues related to guidelines concerning medicine use, but are restricted to the willingness and goodwill of these professionals. Rodrigues et al. (2015) also reported that most users did not receive adequate guidance from pharmacists on how to properly administer medicines.

Nonetheless, the users evaluated in the present study demonstrated that professional friendliness is enough to guarantee satisfaction, as previously shown in literature (Souza Júnior et al., 2015; Ayalew et al., 2017).

Moreover, users report that guidance absence due to insufficient time is possibly because there are few professionals, which are overloaded and only dedicated to "deliver" medicines (Ayalew et al., 2017).

For managers and pharmacists there is a direct relation between salary increase, professionals' satisfaction and performance quality of their activities.

For Silva and Muniz (2011), the excessive number of patients and the lack of material and human resources to perform care, contribute to pharmacist dissatisfaction. This reality was also observed in public services from another municipality, evidencing work overload in public pharmacies (Furquim et al., 2016).

There is a tendency of municipalities to coexist with the high turnover of pharmacists, compromising the presence of qualified and experienced professionals in public services; this makes it difficult to guarantee the quality of medicine use by the population (Barbosa et al., 2017).

From a positive view on the issue addressed, Saberi et al. (2012) reported that pharmacists' insertion into patient care is related to a significant improvement in the treatment and life quality of the patient. In this sense, Rodrigues et al. (2015) showed that the care provided by pharmacists increases compliance with medicine treatment, reduces treatment discontinuation, as well as the number of hospitalizations and visits to emergency care units.

From pharmacists' perspective, the prioritization of managerial actions may require excluding the pharmacist from clinical management (Marin et al., 2003); yet, it is necessary to emphasize that full technical assistance provided by pharmacists can promote the RUM, reducing costs for the health system (Rieck, 2002); however, clinical management, which should be performed by pharmacists, has not yet been consolidated. This may relate to the inappropriateness of the development of this activity, which is added to the profile of a pharmaceutical professional characterized by fear of new responsibilities and aversion to interacting with users (Rosenthal, Austin, Tsuyuki, 2016).

\section{CONCLUSIONS}

According to the evaluation of PS actions performance -assessed through management indicators and data from users, pharmacists and managers- it 
is concluded that Vila Velha's PS has qualities that favor the execution of PS services and that they can be replicated to other municipalities, such as medicine inventory control and friendliness of the professionals who develop pharmacy services.

Nevertheless, many of our data reveal that the structure, processes and results of Vila Velha's PS are insufficient to ensure the ideal performance of the services; therefore, this scenario demonstrates that Vila Velha's municipal PS model is mostly unsatisfactory for users, managers and pharmacists, especially regarding structural and organizational aspects.

Altogether, the results indicate the necessity of improvements in relation to structural, technological, human, and organizational resources, especially in the service offered by HU pharmacies.

\section{LIMITATIONS}

The limitation of this study is the evaluation of the perception of managers. The profile of managers that agreed to participate in the study was mainly constituted by pharmaceutical services professionals, limiting the contribution of external managers' perception of the area.

\section{Acknowledgements}

This study was financed in part by the Coordenação de Aperfeiçoamento de Pessoal de Nível Superior - Brasil (CAPES) - Finance Code 001 and Fundação de Amparo à Pesquisa e Inovação do Espírito Santo (FAPES) (grant number: 220/2018 EDITAL FAPES/CNPq/Decit-SCTIE-MS/SESA N $\mathrm{N}^{\circ}$ 03/2018-PPSUS; and grant number: 0279/2016). The Conselho Nacional de Desenvolvimento Científico e Tecnológico (CNPq) is also acknowledged. We additionally thank the Secretaria Municipal de Saúde de Vila Velha (SEMSA) that allowed the development of this research.

\section{REFERENCES}

Alturki M, Khan, TM. A study investigating the level of satisfaction with the health services provided by the Pharmacist at ENT hospital, Eastern Region Alahsah, Kingdom of Saudi Arabia. Saudi Pharm J. 2013;21(3):225-260.

Alves SMP, Coelho MCR, Borges LH, Massaroni L, Maciel PMA. The flexibilization of employment relationships in the health sector: the reality in a Federal University Hospital in Brazil. Ciência \& Saúde Coletiva. 2015;20(10):3043-3050.

Angonesi D. Pharmaceutical dispensing: an analysis of different concepts and models. Ciência \& Saúde Coletiva. 2008;13(Supl. 0):629-640.

Arruda CAM, Bosi, MLM. Satisfação de usuários da atenção primária à saúde: um estudo qualitativo no Nordeste do Brasil. Interface - Comunic., Saúde, Educ. 2017;21(61):321-332.

Ayalew MB, Taye K, Asfaw D, Lemma B, Dadi F, Solomon H, et al. Patients/Clients Expectattion Towrad and Satisfaction from Pharmacy Services. Journal of Research in Pharmacy Practice. 2017;6(1):21-25.

Barbosa MM, Garcia MM, Nascimento RCRM, Reis EA, Guerra Júnior AA, Acurcio FA, et al. Infrastructure evaluation of Pharmaceutical Services in the National Health System of Minas Gerais. Ciência \& Saúde Coletiva. 2017;22(8):2475-2486.

Bardin L. Análise de conteúdo. Lisboa: Edições 70, 1977. 225 p.

Bonadiman RL, Andrade TU, Santana AF, Lima E, Brasil G, Lenz D, et al. Satisfaction level of users and verification of knowledge of pharmacists in public pharmacies of the Espírito Santo. Ciência \& Saúde Coletiva. 2018;23(2):627-638.

Brasil. Lei $\mathrm{n}^{\circ}$ 8080. Dispõe sobre as condições para a promoção, proteção e recuperação da saúde, a organização e o funcionamento dos serviços correspondentes e dá outras providências. Diário Oficial [da] República Federativa do Brasil. Brasília, DF, 20 set. 1990.

Brasil. Ministério da Saúde. Resolução $\mathrm{n}^{\circ}$ 338. Aprova a Política Nacional de Assistência Farmacêutica. República Federativa do Brasil. Brasília, DF, 06 maio. 2004.

Brasil. Ministério da Saúde. Conselho Nacional de Secretários de Saúde. Assistência Farmacêutica no SUS/Conselho Nacional de Secretários de Saúde. Brasília: CONASS, 2007. 186p. Pág. 11, 12.

Brasil. Ministério da Saúde. Portaria $\mathrm{n}^{\circ} 1$, de 2 de janeiro de 2015. Estabelece a Relação Nacional de Medicamentos Essenciais no âmbito do Sistema Único de Saúde (SUS) por meio da atualização do elenco de medicamentos e insumos da Relação Nacional de Medicamentos Essenciais - RENAME 2012. Diário Oficial da União, Brasília, 2 janeiro. 2015.

Bruns SF, Luiza VL, Oliveira E. A. Gestão da Assistência Farmacêutica em municípios do estado da Paraíba (PB): olhando a aplicação de recursos próprios. Rev. Adm. Pública. 2014;48(3):745-765. 
Cassaro KOS, Heringer OA, Fronza M, Lenz D, Endringer DC, Andrade TU. Level of satisfaction of clients of public pharmacies dispensing high-cost drugs in Espírito Santo, Brazil. BJPS. 2016;52(1):95-103.

Correr CJ, Pontarolo R, Melchiors AC, Souza RP, Rossingnoli P, Fernández-Llimós F. Satisfação dos usuários com serviços da farmácia: tradução e validação do Pharmacy Services Questionnaire para o Brasil. Cad Saúde Pública. 2009;25(1):87-96.

Furquim CF, Oliveira SAAS, Silva RHB, Giansante S, Queiroz RRL. Restructuring and Organization of Public Pharmaceutical Assistance in the Municipality of Tangará da Serra-MT. UNICIÊNCIAS. 2016;20(1):44-49.

Helena ETS, Andersen SE, Menoncin SM. Users insights on about acess to medicines in primary care. Cad. Saúde Pública. 2015;25(1):87-96.

IBGE - Instituto Brasileiro de Geografia e Estatística. Primeiros Dados do Censo 2016: Espírito Santo, 2016. Disponível em $<$ http://cidades.ibge.gov.br/xtras/perfil. php?codmun=320520>. Acesso em: 12 de Novembro de 2017.

Kucukarslan SN, Schommer JC. Patients' expectations and their satisfaction with pharmacy services. JAPHA. 2002;42(3):489-495.

Lefevre F, Lefevre AMC. O discurso de sujeito coletivo: um novo enfoque em pesquisa qualitativa (desdobramentos). Caxias do Sul: Educ, 2003.

Leite SN, Manzini F, Álvares J, Guerra Júnior AA, Costa EA, Acurcio FA, et al. Infrastructure of pharmacies of the primary health care in the Brazilian Unified Health System: Analysis of PNAUM - Services data. Rev. Saúde Públ. 2017;51(Supl. $2: 13 \mathrm{~s})$.

Magarinos-Torres R, Pepe VL, Oliveira MA, Osóriode-Castro CGS. Medicamentos essenciais e processo de seleção em práticas de gestão da Assistência Farmacêutica em estados e municípios brasileiros. Ciênc. Saúde Coletiva. 2014;19(9):3859-3868.

Marin N, Luiza VL, Osório-de-Castro CGS, Machado-dosSantos S. Assistência farmacêutica para gerentes municipais. Rio de Janeiro: Organização Pan-Americana da Saúde/ Organização Mundial da Saúde. 2003. 65-83.

Mendes SJ, Manzini F, Farias MR, Leite SN. Gestão da Assistência Farmacêutica: avaliação de um município catarinense. Revista Eletrônica Gestão \& Saúde. 2015;6(1):4-29.

Pinto CDBS, Osório-de-Castro CGS. Gestão da Assistência Farmacêutica e demandas judiciais em pequenos municípios brasileiros: um estudo em Mato Grosso do Sul. Saúde debate. 2015;39(n. especial):171-183.

Prevedello P, Busato MA. Analysis of the pharmaceutica lassistance cycle in Romelândia, Santa Catarina, Brazil. BJPS. 2014;50(1):155-163.

Rieck EB. Assistência farmacêutica na atenção básica de saúde do estado do Rio Grande do Sul: análise dos indicadores do Plano Estadual de Assistência Farmacêutica Básica. 2002. Monografia (Especialização) - Escola de Saúde Pública Sérgio Arouca, Porto Alegre, RS, 2002.

Rodrigues JPV, Ayres LR, Filipin MDV, Oliveira JCN, Pereira LRL. Impacto do atendimento farmacêutico individualizado na resposta terapêutica ao tratamento antirretroviral de pacientes HIV positivos. Journal of Applied Pharmaceutical Sciences - JAPHAC. 2015;2(1):18-28.

Rosenthal MM, Austin A, Tsuyuki RT. Barriers to pharmacy practice change: Is it our nature or nurture? Canadian Pharmacists Journal. 2016;149(6):317-319.

Rover MRM, Vargas-Peláez CM, Faraco EB, Farias MR, Leite SN. An evaluation of governance capacity of the specialized componente of pharmaceutical services in Brazil. Ciência \& Saúde Coletiva. 2017;22(8):2487-2499.

Saberi P, Dong BJ, Johson MO, Greenblatt RM, Cocohoba JM. The impact of HIV clinical pharmacists on HIV treatment outcomes: a systematic review. NHI-Patient Prefer Adherence. 2012;6:297-322.

Silva RM, Pereira NC, Mendes LVP, Luiza VL. Pharmaceutical services in Rio de Janeiro Municipality, Brazil: development regarding selected aspects from 2008 to 2014. Ciên. Saúde Coletiva. 2016;21(5):1421-1432.

Silva NM, Muniz HP. Experiences of workers in the context of precariousness: a case study in the Emergency of University Hospital. Studies and Research in Psychology. 2011;11(3): 821-840.

Souza Júnior SO, Fortunato MM, Pessoa GR, Pereira AKM, Do Nascimento EGC, Alchieri JC. Humanization expression in the field of primary health. Revista Redes de Cuidados em Saúde. 2015;9(1):1-13.

Tanaka OU, Melo C. Avaliação de programas de saúde do adolescente - um modo de fazer. São Paulo: EDUSP, 2001. 83 p.

Tuzzo SA, Braga CF. The triangulation processo f the research qualitative: meta phenomenon as genesis. Revista Pesquisa Qualitativa. 2016;4(5):140-158. 
Vila Velha. Secretaria Municipal de Saúde. Setor de Planejamento. Plano Municipal de Saúde - PMS: 2014 - 2017/ Secretaria Municipal de Saúde. Vila Velha, 2013. 120 p.

Volpato DC, Padial RB. Avaliação da Assistência Farmacêutica em municípios de uma regional de saúde do Paraná. Revista Saúde e Pesquisa. 2014;7(2):221-232.

Received for publication on $12^{\text {nd }}$ October 2018 Accepted for publication on $28^{\text {th }}$ September 2019 